RASĀYAN J. Chem.

Vol. 13 | No. 4 |2664-2671| October - December | 2020 ISSN: 0974-1496 | e-ISSN: 0976-0083 | CODEN: RJCABP

RJC http://www.rasayanjournal.com http://www.rasayanjournal.co.in

\title{
GREEN SYNTHESIS OF COPPER NANOPARTICLES USING Holoptelea integrifolia FRUIT EXTRACT
}

\author{
Anju ${ }^{1}$, Shruti Sharma ${ }^{2}$, Hari Ram Dhanetia ${ }^{1}$ and Alka Sharma ${ }^{1, *}$ \\ ${ }^{1}$ Centre of Advanced Study, Department of Chemistry, University of Rajasthan, \\ Jaipur-302 004, (Rajasthan) India \\ ${ }^{2}$ Research Fellow, DIC, CCT, University of Rajasthan, Jaipur-302 004, (Rajasthan) India \\ *E-mail : sharma_alka21@yahoo.com
}

\begin{abstract}
Fabrication of green nanoparticles using plant extract is the novel method to develop eco-friendly nanoparticles which can be used in numerous industrial sectors including medical sciences. With this view, copper nanoparticles have been fabricated using Holoptelea integrifolia fruit extract. The extract serves both as a reducing as well as stabilizing agent. The fabricated Copper nanoparticles (CuNPs) were characterized with standard techniques, viz., Fourier transform infrared spectrometer (FTIR), UV-vis spectrophotometer, and surface morphology was investigated by Scanning Electron Microscope (SEM). The active phytochemicals (terpenoids, flavonoids, proteins etc.) present in the Holoptelea integrifolia fruit extract were considered to be solely responsible for the formation as well as for the stabilization of copper nanoparticles. Green route for fabrication of copper nanoparticles avoids high temperature, high pressure, laser radiation, inert gases, toxic chemicals etc. as compared to traditional methods, thus conserving environment, energy and economy.
\end{abstract}

Keywords: Copper Nanoparticles, Holoptelea integrifolia, FTIR, UV-Visible, SEM

(C) RASĀYAN. All rights reserved

\section{INTRODUCTION}

In the present era of advanced sciences and technology, Nanotechnology and Nanoscience have emerged as a new area. Nanotechnology and nanoscience is now receiving global recognition due to its extensive applications applied to almost all spheres of life ranging from nanoelectronics, nanomedicine, defense equipments, transformations, heat transfer to sports, aesthetics etc.

It is well recognized that metallic nanoparticles (MNPs) hold distinctive properties such as electronic, magnetic, optical, and catalytic, very much different from the micro sized bulk materials, owing to which it has multiple applications in household, agricultural, and industrial sectors. ${ }^{1-3}$ Usually, routine methods are employed for the fabrication of nanoparticles, such as, laser ablation, ${ }^{4}$ high energy ball billing, arc discharged, chemical vapour deposition methods, co-precipitation method, thermal reduction, ${ }^{6}$ micro emulsion method, ${ }^{7}$ sol-gel method ${ }^{8}$ etc. Conversely, all these routine methods consume much of energy and are costlier too. Moreover, due to consumption of many toxic chemicals, non polar solvents and synthetic additives or capping agents, these methods are toxic to the environment which may also hamper their usages in clinical and biomedical fields. All these parameters led to develop a 'green' and 'bioprocesses' methodology to synthesize nanoparticles which is clean, ecofriendly, reliable, and biocompatible. ${ }^{9}$

Green synthesis of nanoparticles is a bottom up technique involving three major steps: selection of reaction medium, selection of biological reducing agent, and selection of non-carcinogenic stabilizing substances. ${ }^{10}$ It usages extract of fruits, leaf, agricultural wastes, microorganisms, fungi, enzymes etc. ${ }^{11-15}$ Plant based green synthetic approach has more advantages over other bio-based synthetic routes. The natural resources have great innate prospective to reduce metals into nanoparticles without using toxic and hazardous chemicals. Green fabrication-approach offers advantages of superior biocompatibility in contrast to routine physical and chemical approaches and thus has better scope for biomedical and other industrial applications. The phytochemicals with active biomolecules, viz., vitamins, amino acids,

Rasayan J. Chem., 13(4), 2664-2671(2020)

http://dx.doi.org/10.31788/ RJC.2020.1346306

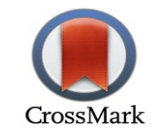


RASĀYAN J. Chem.

Vol. 13 | No. 4 |2664-2671| October - December | 2020

proteins, polyphenols, flavones, terpenoids, polysaccharides, alkaloids, tannins, saponins, etc to act as corrosion inhibitors ${ }^{16-23}$ as well as reducing and capping agent to fabricate nanoparticles. ${ }^{24}$

The synthesis of copper based nanoparticles has been carried out via green approach employing various plant extracts. ${ }^{25-35}$ Owing to the versatile usages of copper nanoparticles in numerous bio- and industrial sectors, it was focused to investigate the fabrication of green copper nanoparticles using extract of Holoptelea integrifolia, commonly known as Indian Elm Tree, which is a well known glaborous deciduous tree. Holoptelea integrifolia possess chemical constituents like terpenoids, sterols, saponins, tannins, proteins, carbohydrates, alkaloids and flavonoids. ${ }^{36-37}$
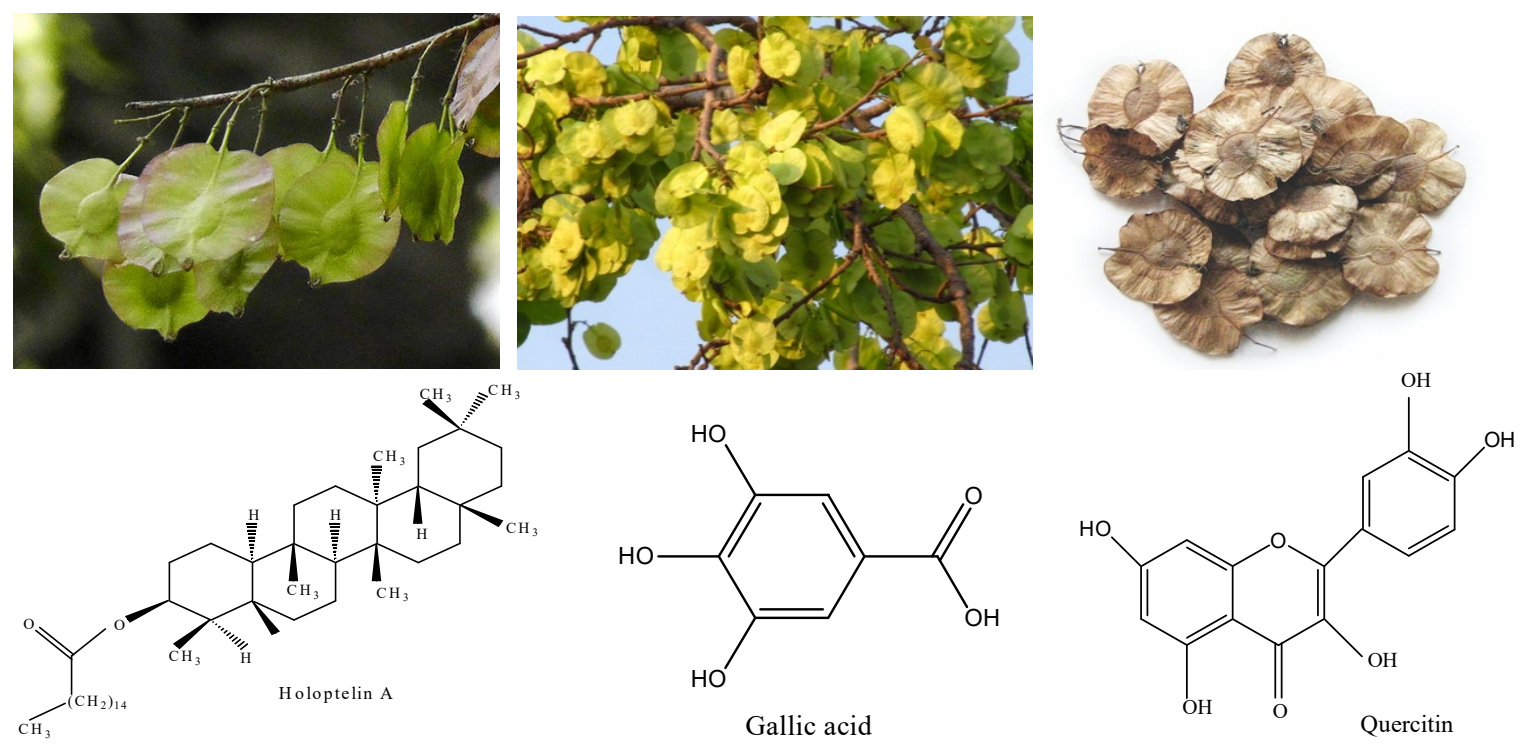<smiles>O=C1C=CC(=O)c2ccccc21</smiles>

1,4 -naphthaquinone<smiles>O=c1c(OC2OC3C(O)C(O)C(O)C2(O)C3O)c(-c2ccc(O)c(O)c2)oc2cc(O)cc(O)c12</smiles>

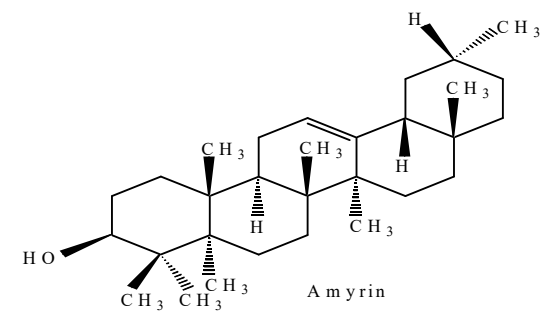

Fig.-1: Some of the Major Phytochemicals of Holoptelea integrifolia

\section{Materials and Methods}

\section{EXPERIMENITAL}

All the primary metal salts and all the other chemicals used in this work were of AR grade. Copper sulphate pentahydrated $\left(\mathrm{CuSO}_{4} .5 \mathrm{H}_{2} \mathrm{O}\right)$ from Sigma Aldrich was used for standard metal salt solutions as precursor. Triple distilled and DI water was used in the entire experimental work. Holoptelea integrifolia fruits were collected from campus of University of Rajasthan, Jaipur, India.

\section{Preparation of aqueous extract of Holoptelea integrifolia}

Fresh and healthy fruit of $H$. integrifolia were collected, washed with running tap water and re-washed with distilled water to remove any dirt or dust or unwanted material adhered on them. Fruits were cut into small pieces, shade dried and then crushed to fine powdered form with the help of mixer grinder. Approximately 30-35 g of finely powered $H$. integrifolia fruits was refluxed using Soxhlet extractor for many cycles. Fine colloidal extract was centrifuged for half an hour and then filtered using Whatmaan 
RASĀYAN J. Chem.

Vol. 13 | No. 4 |2664-2671| October - December | 2020

No. 1 to remove particulate matter. This clear dark brown extract solution was used as stock solution for further use in experimentation.

\section{Fabrication of Copper Nanoparticles (GNPs) using stocked $\boldsymbol{H}$. integrifolia Extract}

The stocked $H$. integrifolia extract and $0.01 \mathrm{M} \mathrm{CuSO}_{4}$ solution were mixed in 2:1 ratio in a conical flask and the mixture is subjected to the magnetic stirrer for atleast 2 hours. Within a sometime, the change in colour was noted from dark brown to green which is treated as preliminary indication of reduction of metallic salt thereby formation of nanoparticles. ${ }^{25-35}$ The reaction mixture was repeatedly centrifuged at 10000 rpm@15 min, filtered and washed in distilled ethanol for effective collection of reduced metal particles. The sediment was collected, vacuum dried in an oven and stored in a clean sterilized glass vial for further characterization. Oven-dried metallic nanoparticles were investigated through standard characterization tools and techniques, viz., FTIR, UV-Vis spectroscopy, SEM to get details on particles/crystals.

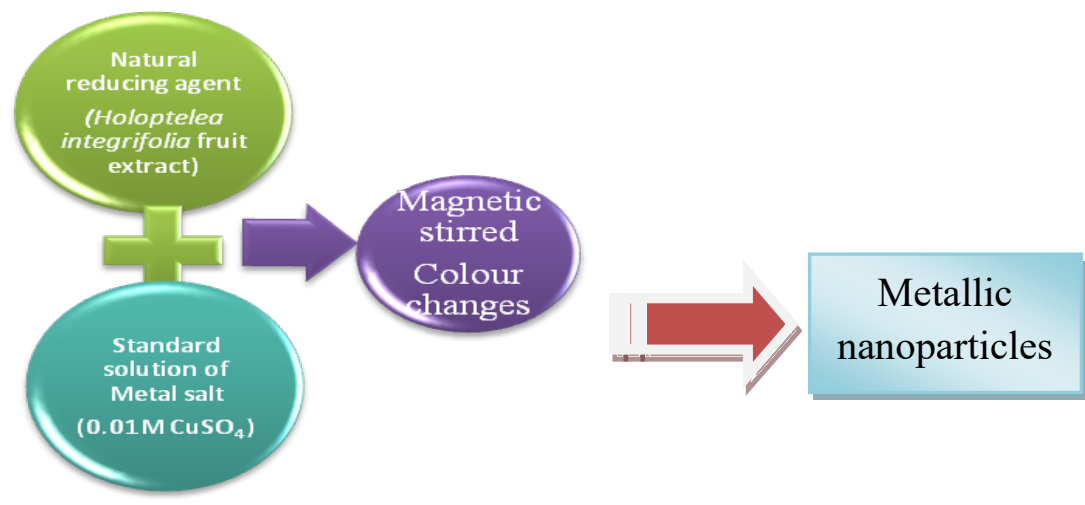

\section{Detection Method}

Fig.-2: Schematic Green Synthesis of Nanoparticles

The reduction of metallic salts in to nanoparticles can be very well justified from the preliminary parameters, viz., change in colour and $\mathrm{pH}$ of the reaction mixture. Further validation of nanoparticles formation was carried out by doing characterizations using FTIR, UV-Vis spectroscopy, SEM-EDX, etc.

Apart from basic laboratory instrumentations, viz., digital $\mathrm{pH}$ meter (Remi), heater cum magnetic stirrer (Remi), Soxhlet extractor, heating mantle, a high speed centrifuge (Remi RM12C BL) etc., some sophisticated standard instruments were used for characterization, namely, Ocean optic HR 4000 High Resolution UV-Vis spectrophotometer, Spectrum Two FTIR Spectrometer (PerkinElmer), Nova Nano FE-SEM 450 (FEI) ZEISS, etc.

\section{Visual Parameter-The Colour Change}

\section{RESULTS AND DISCUSSION}

The prelim indications of formation of copper nanoparticles using aqueous extract $H$. integrifolia was visible by the change in the colour of the reaction mixture from dark brown to dark green within half an hour after stirring. The weakening in intensity of brown colour to green was owing to the excitation of surface Plasmon vibrations of copper nanoparticles.
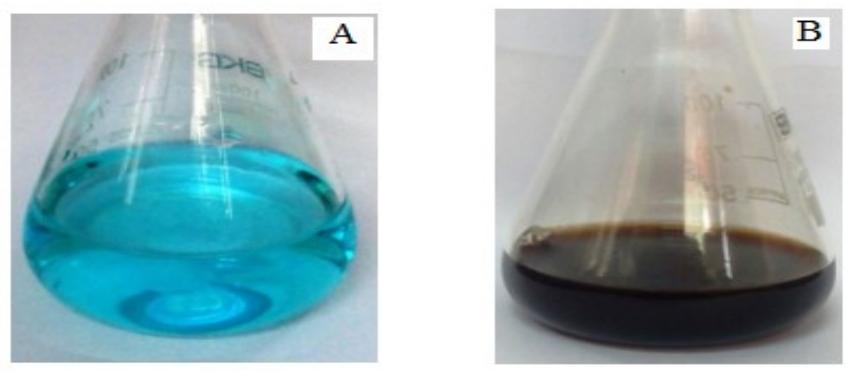

2666

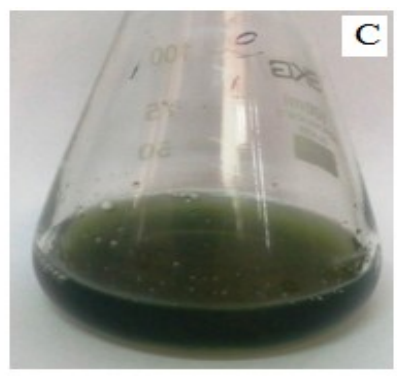

Anju et al. 
RASĀYAN J. Chem.

Vol. 13 | No. 4 |2664-2671| October - December | 2020

Fig.-3: Change in Colour of the Reaction Mixture pH Analysis

[Flasks: A: Std solution of $\mathrm{CuSO}_{4}-5 \mathrm{H}_{2} \mathrm{O}, \mathrm{B}$ : H. integrifolia fruit extract, C: Reaction mixture]

The reduction of the metallic salt is a $\mathrm{pH}$ dependent process. Therefore, the $\mathrm{pH}$ of the precursor solutions and the reaction mixture were observed using Remi Digital $\mathrm{pH}$ meter. The $\mathrm{pH}$ of the standard metal salt solution $\left(\mathrm{CuSO}_{4} .5 \mathrm{H}_{2} \mathrm{O}\right)$ was observed as 4.55 whereas the $\mathrm{pH}$ of the reduced reaction mixture with synthesized nanoparticles was found to be 5.62 .

\section{Characterization of Synthesized Green Copper Nanoparticles}

After preliminary observations of the fabricated nanoparticles, with utmost care they were properly collected vacuum dried in a hot oven and analyzed employing standard spectroscopic techniques.

\section{UV-Visible Spectroscopic Analysis}

The fabricated green copper nanoparticles were characterized through Ocean optic HR 4000 HighResolution UV-Vis spectrophotometer with range of absorbance from 200-800 nm.

The bioreduced aqueous reaction mixture was characterized through UV-Visible spectra of the solution. The UV-Visible spectral analysis is a convenient, preliminary and indirect method for characterization of $\mathrm{Cu}$ nanoparticles based on optical properties called surface Plasmon resonance (SPR). ${ }^{30-33}$ The initiation of reaction was endorsed by observing color of the extract which turns turbid on addition of copper sulphate solution. The green nanoparticles thus formed was exemplified by UV-Visible absorption spectra and a broad absorbance peak at 350-410nm was observed. This broad peak centered between 350$410 \mathrm{~nm}$ was clearly indicative of the formation of copper nanoparticles. The bio-reduction of the copper ions must be due to the presence of active bio-molecules, viz., 1,4-naphthquinone, gallic acid, quercitrin, quercitin, etc. This was further validated through FTIR spectroscopic data also.

$$
\mathrm{Cu}^{2+}+\text { bio-molecules } \rightleftharpoons \mathrm{Cu}^{0}
$$

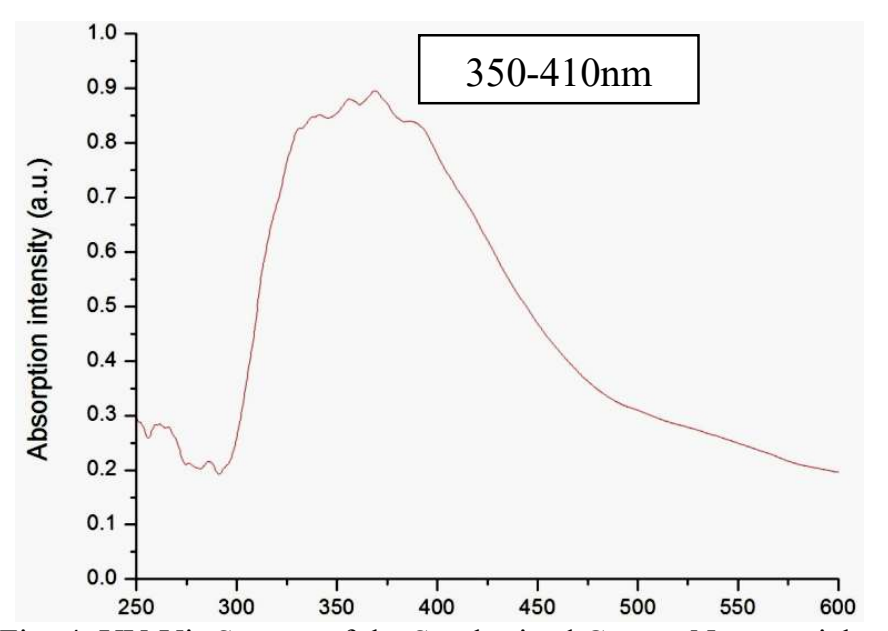

\section{FTIR Spectroscopic Analysis}

Fig.-4: UV-Vis Spectra of the Synthesized Copper Nanoparticles

To determine the active phytochemicals present in the Holoptelea integrifolia fruit extract which are responsible for the reduction of Copper ions and their apparent oxidative stability, FTIR spectral analysis was carried out in the spectral range of $400-4000 \mathrm{~cm}^{-1}$. Here the vacuum dried sample of fabricated nanoparticles was grounded with $\mathrm{KBr}$ to form a pellet and then analyzed using Spectrum Two FTIR Spectrometer (PerkinElmer).

The FTIR spectroscopy reveal about functional groups of the active phytochemicals present in the extract which reduces the copper ion. FTIR spectrum as shown in Fig.-5 $(\mathrm{a}, \mathrm{b})$ which clearly illustrates the active 
RASĀYAN J. Chem.

Vol. 13 | No. 4 |2664-2671| October - December | 2020

phytochemicals present in the extract are responsible for the eco-friendly green synthesis of Copper nanoparticles as they act as reducing, stabilizing and capping agents.

A number of adsorption peaks were observed in the spectrum of Holoptelea integrifolia fruit extract (Fig.5a), reflecting its complex nature. The comparison of FTIR spectrum of the extract and that of the synthesized nanoparticles (Fig.-5b) can yield information about reducing agents responsible for metallic ion reduction. In the spectrum of Holoptelea integrifolia fruit extract (Fig.-5a), the broad absorption peak at $3625 \mathrm{~cm}^{-1}$ corresponds to the stretching vibration of hydroxyl $(\mathrm{OH})$ group in alcohols and phenolic compounds. The IR band around $1575 \mathrm{~cm}^{-1}$ and $1640 \mathrm{~cm}^{-1}$ can be assigned to aromatic bending of $\mathrm{C}=\mathrm{C}$ group and $\mathrm{C}=\mathrm{O}$ group respectively and $2755 \mathrm{~cm}^{-1} \mathrm{C}-\mathrm{H}$ stretching. The peak at $595,460 \mathrm{~cm}^{-1}$ is due to metal-carbon stretch. Many of these peaks were shifted or replaced with new peaks after the reaction of extract with metal salt solution was over as clearly observed in Fig. 5b. There were new bands observed corresponding to hydroxyl band owing to scissor bending vibration of molecular water, acidic asymmetric stretch, etc.

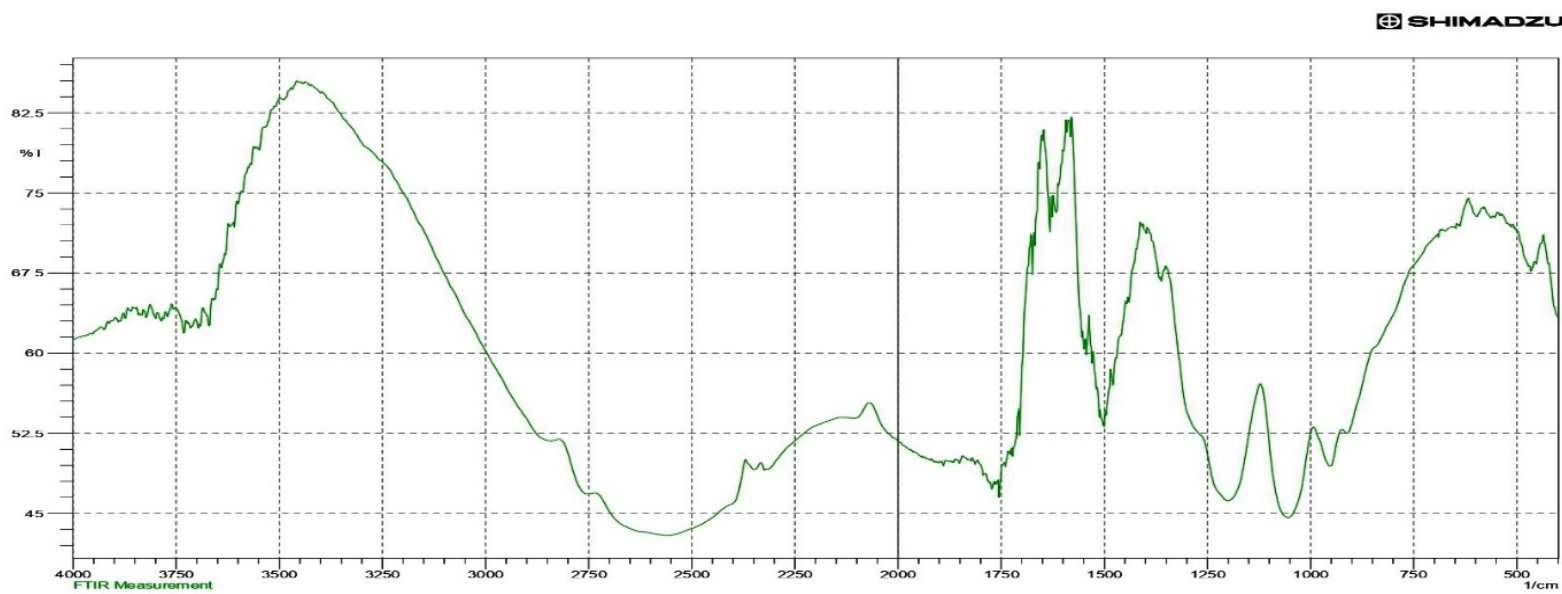

Fig.-5a: FTIR Spectrum of Holoptelea Integrifolia Fruit Extract.

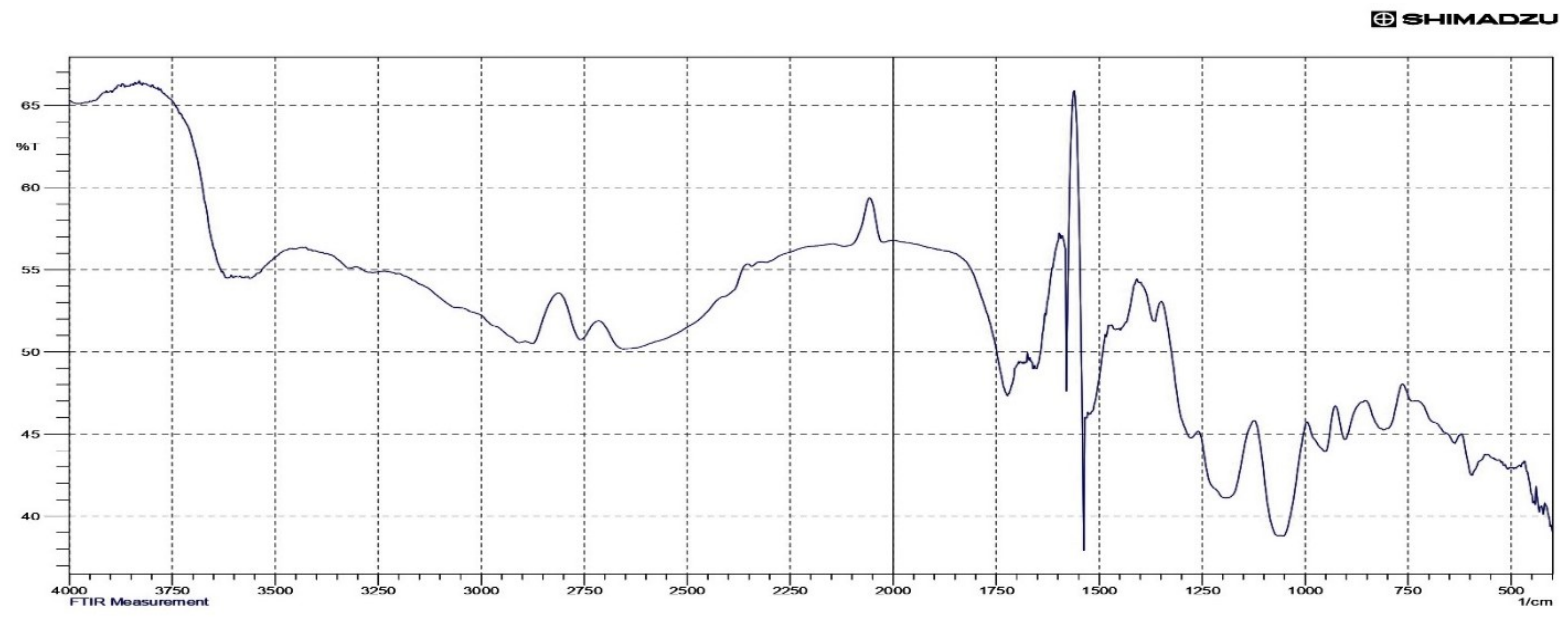

Fig.-5b: FTIR Spectrum of Reaction Mixture of H. integrifolia mediated Copper Nanoparticles.

The active phytochemicals present in fruit extract such as polyphenols, flavonoids, alcoholic, phenolic groups has significant propensity to bind metal. Moreover, for the synthesized green metal nanoparticles, these active bio-molecules also serve as capping agent to avoid agglomeration, thereby stabilize the medium. It can be very well projected that the bio-chemicals present in indigenous plant/plant parts serves to fabricate and stabilize the copper nanoparticles. 
RASĀYAN J. Chem.

Vol. 13 | No. 4 |2664-2671| October - December | 2020

\section{Scanning Electron Microscopic (SEM) Analysis}

The Scanning Electron Microscopy (SEM) analysis was used to investigate the surface morphology as well as the size of the nanoparticles.

Thin films of the sample were analyzed by carrying out SEM images at the magnifications of $20 \mu \mathrm{m}$ (Fig. 6a) and $10 \mu \mathrm{m}$ (Fig. 6b). SEM micrographs of synthesized copper nanoparticles employing extract of Holoptelea integrifolia depicted as Fig. $6(\mathrm{a}, \mathrm{b})$ which clearly reveal that most of the nanoparticles are spherical in nature and were formed in cluster. However, further magnification reveals that these copper nanoclusters are groups of smaller nanoparticles exhibiting good uniformity.
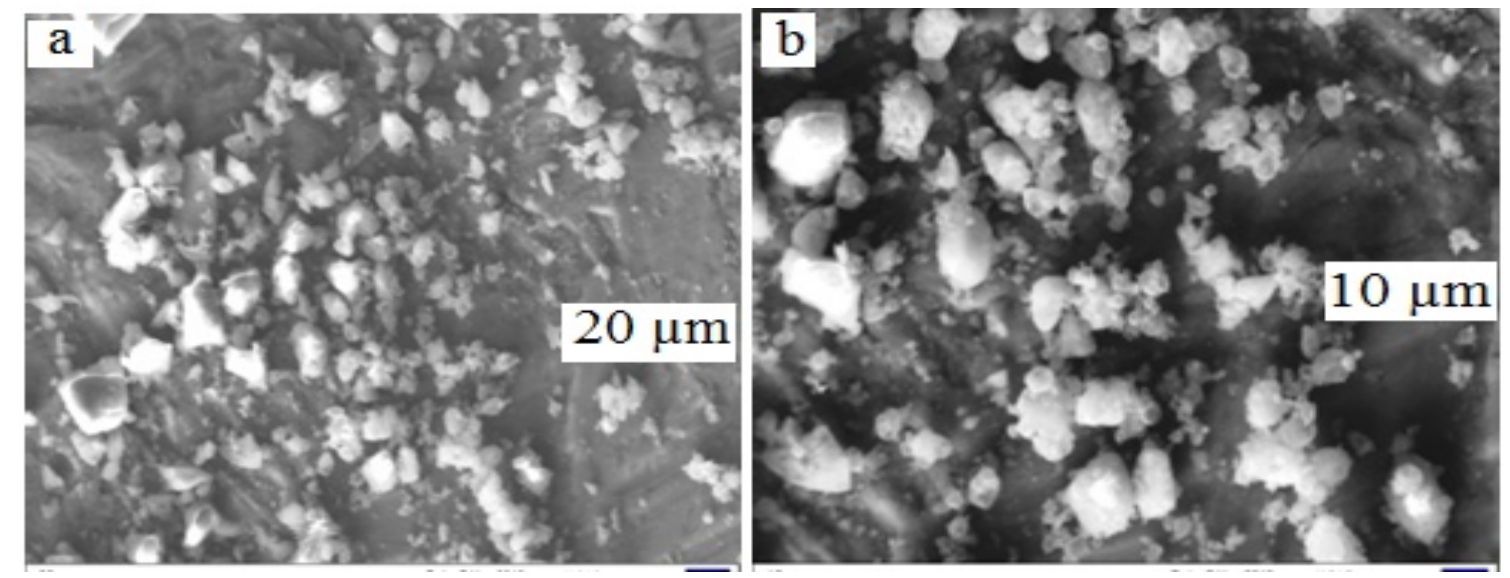

Fig.-6: SEM Micrographs of Fabricated Nanoparticles taken at (a) $20 \mu \mathrm{m}$ and (b) $10 \mu \mathrm{m}$.

\section{CONCLUSION}

Fabrication of copper nanoparticles was carried out using Holoptelea integrifolia fruit aqueous extract at room temperature through a cost-effective, time saving, easier and environmentally benign route. It is a novel bio-synthesis technique which does not involve any toxic chemicals as used in conventional chemical reduction processes. The standard characterization analyses carried by UV-Visible spectroscopy, FTIR spectroscopy, and SEM reveal the successful fabrication of green copper nanoparticles.

The active phytochemicals present in the Holoptelea integrifolia extract not only reduce the metal ions, but also stabilize the copper nanoparticles and prevent them getting oxidized post synthesis. The biogenic method has merits over other reported conventional methods as the natural resources are indigenous, abundantly available precursors, inexpensive, with easy to carry out procedure in any laboratory, use of non-toxic reagents and a reliable pollution free process. Besides, these green nanoparticles have abundant applications in various sectors of bio-medical and other industries.

\section{ACKNOWLEDGEMENT}

This work has been financially supported by the CSIR for which the author is highly thankful. Authors also expresses thanks to the Head, Department of Chemistry, and Director, USIC, University of Rajasthan, Jaipur for providing necessary research facilities.

\section{REFERENCES}

1. N. Pantidos, L. E. Horsfall, Journal of Nanomedicine \& Nanotechnology, 5(5), 1(2014), DOI: $10.4172 / 2157-7439.1000233$

2. J. R. Peralta-Videa, Y. Huang, J. G. Parsons, L. Zhao, M. L. Lopez-Moreno, J. A. Hernandez Viezcas, J. L. Gardea-Torresdey, Nanotechnology for Environmental Engineering, 1(1), 4(2016), DOI: $10.1007 / \mathrm{s} 41204-016-0004-5$

3. M. Ahmadi, H. Mistry, B. R. Cuenya, Journal of Physical Chemistry Letters, 7(17), 3519(2016), DOI:10.1021/acs.jpclett.6b01198 
RASĀYAN J. Chem.

Vol. 13 | No. 4 |2664-2671| October - December | 2020

4. Jiaxin Yu, Junyi Nan, Heping Zeng, Applied Surface Science, 402, 330(2017), DOI: 10.1016/j.apsusc.2017.01.0940

5. P. K. Singh, A. K. Das, G. Hatui, G. C. Nayak, Materials Chemistry and Physics, 198, 16(2017), DOI: 10.1016/j.matchemphys.2017.04.070

6. R. Betancourt-Galindo, P. Y. Reyes-Rodriguez, B. A. Puente-Urbina, C. A. Avila-Orta, O. S. Rodríguez-Fernández, G. Cadenas-Pliego, R. H. Lira-Saldivar, L. A. García-Cerda, Journal of Nanomaterials, 2014, 1(2014), DOI:10.1155/2013/980545

7. A. Khan, A. Rashid, R. Younas, R. Chong, International Nano Letters, 6, 21(2016), DOI: 10.1007/s40089-015-0163-6

8. Penny Mathumba, A. T. Kuvarega, L. N. Dlamini, S. P. Malinga, Materials Letters, 195, 172(2017), DOI: 10.1016/j.matlet.2017.02.108

9. Oxana V. Kharissova, H. V. Rasika Dias, Boris I. Kharisov, Betsabee Olvera Perez, Victor M. Jimenez Perez, Trends in Biotechnology, 31(4), 1(2013), DOI: 10.1016/j.tibtech.2013.01.003

10. L Karthik, A. Vishnu Kirthi, Shivendu Ranjan, V. Mohana Srinivasan, Biological Synthesis of Nanoparticles and Their Applications. CRC Press, US (2020).

11. V. V. Makaro, A. J. Love, O. V. Sinitsyna, S. S. Makarova, I. Yaminsky, M. E. Taliansky, and N. O. Kalinina, ActaNaturae, 6(1), 35(2014), DOI:10.32607/20758251-2014-6-1-35-44

12. B. Kumar, K. Smita, L. Cumbal, A. Debut, Y. Angulo, Journal of Saudi Chemical Society, 21, S475(2017), DOI:10.1016/j.jscs.2015.01.009

13. Priyanka Singh, Yu-Jin Kim, Dabing Zhang, Deok-Chun Yang, Trends Biotechnology, 34(7), 588(2016), DOI:10.1016/j.tibtech.2016.02.006

14. B. Kumar, K. Smita, L. Cumbal, and A. Debut, Saudi Journal of Biological Sciences, 24(1), 45(2017), DOI:10.1016/j.sjbs.2015.09.006

15. Z. U1 Haq Khana, A. Khan, Y. Chen, N. S. Shaha, N. Muhammad, A. Ullah Khanb, K. Tahirf, F. Ullah Khanb, B. Murtazaa, S. U1 Hassane, S. A. Qaisrania, P. Wan, Journal of Photochemistry and Photobiology B: Biology, 173, 150(2017), DOI:10.1016/j.jphotobiol.2017.05.034

16. Shashi Sharma, Prassan S. Parihar, Monika, Rekha N. Nair, P. S. Verma and Alka Sharma, Rasayan Journal of Chemistry, 5(1), 16(2012).

17. Prassan Singh Pratihar, Monika, P. S. Verma, and Alka Sharma, Rasayan Journal of Chemistry, 8(4), 411(2015).

18. Monika, Guddi Choudhary, Anju, Alka Sharma, International Journal of Innovative Research in Science, Engineering and Technology, 5(12), 21064(2016), DOI:10.15680/IJIRSET.2016.0512159

19. B. S. Swaroop, S. N. Victoria, R. Manivannan, Journal of the Taiwan Institute of Chemical Engineers, 64, 269(2016), DOI:10.1016/j.jtice.2016.04.007

20. Monika, Anju and Alka Sharma, International Journal of Science and Research, 6(12), 1952(2017), DOI: $10.21275 / 11011702$

21. P. E. Alvarez, M. V. Fiori-Bimbi, A. Neske, S. A. Brandan, C. A. Gervasi, Journal of Industrial and Engineering Chemistry, 58, 92(2018), DOI:10.1016/j.jiec.2017.09.012

22. Komal Choudhary, Arpita Sharma, Monika, Anju, Alka Sharma, International Journal for Research in Applied Science \& Engineering Technology, 6(XII), 843(2018).

23. H. Hassannejad, A. Nouri, Journal of Molecular Liquids, 254, 377(2018), DOI:10.1016/j.molliq.2018.01.142

24. S. Ahmed, Saifullah, M. Ahmad, B. L. Swami, S. Ikram, Journal of Radiation Research and Applied Sciences, 9(1), 1(2016), DOI:10.1016/j.jpras.2015.06.006

25. Manoj B. Gawande, Anandarup Goswami, Francois-xavier Felpin, Tewodros Asefa, Xiaoxi Huang, Rafael Silva, Xiaoxin Zou, Radek Zboril, Rajender S. Varma, Chemical Reviews, 116(6), 3722 (2016), DOI:10.1021/acs.chemrev.5b00482

26. J. Fernando, P. Gurulakshmi, Journal of Nanoscience and Technology, 2(5), 234(2016), DOI:10.13140/RG.2.2.18292.19842

27. J. Suarez-Cerda, H. Espinoza-Gomez, G. Alonso-Nunez, I. A. Rivero, Y. Gochi-Ponce, L. Z. FloresLopez, Journal of Saudi Chemical Society, 21, 341(2017), DOI:10.1016/j.jscs.2016.10.005 
RASĀYAN J. Chem.

Vol. 13 | No. 4 |2664-2671| October - December | 2020

28. J. Singh, T. Dutta, Ki-Hyun Kim, M. Rawat, P. Samddar, P. Kumar, Journal of Nanobiotechnology, 16(84), 1(2018), DOI:10.1186/s12951-018-0408-4

29. V. Patwardhan Siddharth, R. H. Manning Joseph and Chiacchia Mauro, Current Opinion in Green and Sustainable Chemistry, 12, 110(2018), DOI:10.1016/j.cogsc.2018.08.004

30. Zahra Vaseghi, Omid Tacakoli, Ali Nematollahzadeh, Journal of Environmental Chemical Engineering, 6(2),1898(2018), DOI:10.1016/j.jece.2018.02.038

31. N. V. K. P. Panduranga, U. Shameem, K. R. Lakshmi, K. Pratap, K. Sharmila, S. V. N. Pammi, SN Applied Sciences, 1(5), 421(2019), DOI:10.1007/s42452-019-0449-9

32. V. Zahra, T. Omid, N. Ali, Korean Journal of Chemical Engineering, 36(3), 489(2019), DOI: $10.1007 / \mathrm{s} 11814-018-0216-4$

33. V. Zahra, N. Ali, T. Omid, Journal of the Taiwan Institute of Chemical Engineers, 96, 148(2019), DOI: $10.1016 /$ j.jtice.2018.10.020

34. C. F. Radu, O. Alina, M. A. Sorin, F. Irina, Molecules, 24(3418), 1(2019), DOI: $10.3390 /$ molecules24193418

35. N. Mahmoud, A. Reza, I. Zahra, S. M. Sajadi, Ceramics International, 46(2), 2093(2020), DOI: $10.1016 /$ j.ceramint.2019.09.191

36. J. Srivastava, S. K. Prasad, K. N. Dwivedi, H. P. Pandey, International Journal of Pharmaceutical Sciences Review and Research, 21(2), 281(2013).

37. S. Khalid, H. Yasin, Natural Products Chemistry \& Research, 2(1), 1(2013), DOI: 10.4172/23296836.1000124

[RJC-6306/2020] 